\title{
A ESCRITA ANTICOLONIALISTA DE LUÍS BERNARDO HONWANA
}

\author{
Vércia Gonçalves Conceição*
}

RESUMO: Este artigo tem como intenção traçar um perfil mais completo do escritor Luís Bernardo Honwana. Falar sobre a escrita e a biografia desse autor é algo relevante, pois mesmo tendo ele publicado uma única obra literária, o Nós Matamos o Cão-Tinhoso (1964), trata-se de um texto e um escritor emblemáticos. No entanto a historiografia e a crítica que dá conta das produções africanas do período colonial apresenta um material insipiente sobre sua vida, sua obra, não permitindo, ao pesquisador das literaturas moçambicanas, um contato mais significativo com o cenário em que surge. Além de uma compilação do material que foi publicado em lugares diferentes (Portugal, Macau, Moçambique e Brasil), com informações reduzidas, mas com dados diferentes, este texto faz uma reflexão sobre o papel de intelectual e de político exercido pelos escritores da geração de Honwana.

PALAVRAS-CHAVE: Perfil. Honwana; Nós matamos o Cão-Tinhoso; Literatura anticolonial.

Luís Bernardo Honwana nasceu em Lourenço Marques, no ano de 1942, e em seguida sua família foi morar no interior do país - província ultramarina portuguesa -, mas em 1959, Honwana volta à capital para dedicar-se à atividade jornalística. O autor era amigo de Craveirinha, com quem, além de animar a cena intelectual de Lourenço Marques, dividiu a experiência da prisão política, que se deu no período de 1964 até 1967 (BUCAIONI, 2015, p. 297). Sobre essa prisão, o próprio Honwana explica que não teve muito a ver com a atividade literária, mas política, de fato:

\footnotetext{
* Professor-formador na Universidade Aberta, pela Universidade do Estado Bahia (Uneb). Doutorando em Letras pela Universidade Federal da Bahia (Ufba).
} 
A publicação do livro gerou muita polémica em Moçambique, mas não creio que a minha prisão tenha directamente a ver com os meus escritos. O livro só teve a sua circulação "desencorajada" pelas autoridades coloniais muito mais tarde, em 1965, após o fechamento em Portugal da Sociedade Portuguesa de Autores, na sequência da premiação do "Luanda" de Luandino Vieira. (HONWANA, ANEXO A)

Conforme Maria Leonor Nunes (2010a)ํㅜㄹ além do curso de Jornalismo, Honwana tem formação em Direito, Pintura e Cinema, também foi um exímio atleta. Viveu sempre como cidadão dos dois mundos presentes em Moçambique, caindo num "verdadeiro caldo cultural". A jornalista portuguesa explica que o autor cresceu num ambiente bilíngue, pois viveu no espaço rural durante a infância e, por isso, relaciona-se com a língua materna, o ronga, mas também ouvia desde pequeno o português, já que seu pai era intérprete da administração. Nunes sugere que a militância de Honwana vem de família, pois seu avô participou na organização do movimento da África do Sul, dirigido mais tarde por Mandela, em Moçambique, e seu pai foi um dos primeiros presos políticos moçambicanos, o que justifica sua tendência à militância.

Segundo Marco Buacaioni (2015), Honwana publicou Nós Matamos o Cão-Tinhoso em 1964, aos 22 anos, e nunca mais voltou a publicar literatura. Será, então, que poderíamos considerar sua escrita, conforme Chabal, como de "circunstância" e tratá-lo como um escritor que tem sua motivação literária, como apresentou Fanon, marcada pela necessidade de tirar o povo da letargia? Optamos por não trabalhar com classificações de sua obra, mas por propor um perfil do escritor, que tem seu papel de intelectual, tangenciado pela cultura e pela política. Uma característica que percebemos não só em Honwana, mas em muitos dos escritores africanos, que, ao escrever literatura, não produz ficção, apenas. Tratam-se de relevantes reflexões e problematizações sobre a história, a política e a cultura de seus hoje - países. 
Começamos por Edward W. Said (1993), em Representações do intelectual, uma proposta de descrição do intelectual muito interessante para a reflexão que pretendemos fazer aqui. Ele apresenta esse sujeito, o intelectual, como "um indivíduo dotado de uma vocação para representar, dar corpo e articular uma mensagem, um ponto de vista, uma atitude, filosofia ou opinião para (e também por) um público" (SAID, 1993, p. 25). Que é a forma que vemos Luís Bernardo Honwana: um escritor-intelectual moçambicano, que utilizou do texto literário para subverter o discurso colonial e alimentar o movimento pela descolonização do território, falando em nome do povo e não em nome do poder.

Said adverte que, para exercer esse papel, o intelectual não pode deixar-se ser cooptado por governos ou corporações, pois é ele que terá a incumbência de confrontar, mais que produzir, "ortodoxias e dogmas", pois sua função é "representar todas as pessoas e todos os problemas que são sistematicamente esquecidos ou varridos para debaixo do tapete" (SAID, 1993, p. 26). Para ele, o intelectual precisa "causar embaraço", precisa ser uma figura representativa, ou seja, precisa simbolizar um ponto de vista e articular figurações para determinado público, por isso, segundo expõe, são pessoas com tendência para a arte de significar "escrevendo, falando, ensinando ou aparecendo na televisão", com o objetivo de "promover a liberdade humana e o conhecimento", alinhando-se aos oprimidos e aos sem representação.

Chama a atenção, no texto de Said, a necessidade de se falar sobre intelectuais a partir das variantes nacionais, religiosas e continentais das questões que, para ele, exigem considerações separadas. Para Said, conceituar o intelectual de forma universal é centrar essa atividade como tipicamente europeia, o que seria, segundo ele, incorrer no mesmo engano de Julien Benda, em Traição dos intelectuais (1929), que possuía seu interesse por intelectuais, considerando apenas os europeus. Mas Said adverte que se faz necessário "colocar questões, estabelecer distinções, recuperar a memória de todas aquelas coisas que tendem a ser desprezadas ou deixadas no limbo, na ânsia de um julgamento e uma ação coletivos" (SAID, 1993, p. 44). Said explica, sobre a ideia do nacional ou de qualquer identidade de grupo, que o intelectual moderno tem o dever de mostrar que se trata de um processo 
de construção, fabricação ou mesmo invenção, com base em história de lutas e conquistas do passado, passíveis de representação.

Nesse sentido, o crítico faz uma reflexão considerando a situação do intelectual em momento como o da guerra de libertação, ele cita o caso da Argélia e pondera, dizendo não ser suficiente a participação do intelectual apenas fazendo coro ao anticolonialismo. Para ele, é necessária a análise das escolhas, recaindo sobre o objetivo, que, na esteira dos pressupostos de Fanon e Césaire, conclui que seria a invenção de novas almas. Said faz um alerta ao fato de o intelectual não deixar que a lealdade à luta anestesie seu senso crítico, pois mesmo entre os oprimidos, segundo ele pontua, existem vencedores e perdedores, por isso o intelectual não se deve restringir ao objetivo coletivo, pois a crítica à liderança precisa continuar existindo, mesmo sendo esse líder um ex-colonizado.

Podemos considerar que Honwana cumpre com esse quesito proposto por Said, pois ele continua exercendo seu papel de intelectual, que fala e escreve, pensando no povo mais desprovido de atenção, no contexto pós-independência de Moçambique. Embora tenha atuado pela FRELIMO contra a colonização, sendo um porta-voz dos colonizados e depois assumindo cargos políticos pelo partido, agora ele coloca-se em nome do povo moçambicano, pensando, ainda de forma crítica, a cultura e a unidade nacional num formato inclusivo e plural, para o atual contexto.

Said pontua, ainda, que romancistas, pintores e poetas, enquanto intelectuais, representaram o sofrimento de uma coletividade da qual eram parte, testemunhando lutas e reforçando sua memória, ao projetarem nas obras de arte as experiências históricas do seu povo. Sugere que essa tarefa do intelectual, assim, universaliza crises e conflitos de determinada nação, associando-as às experiências de outros povos. Ele defende que, com isso, não há perda de especificidade histórica, mas uma prevenção, já que uma experiência de opressão de determinado tempo e lugar poderá ser lembrada num outro momento, em outro lugar, evitando, assim, a repetição da história de sofrimento, que causa traumas para uma nação. Honwana é esse intelectual do qual Said nos fala. Através de Nós matamos o Cão- 
Tinhoso, ele representa o sofrimento, mas também a luta do colonizado moçambicano, coletividade da qual ele participa e pela qual ele fala. É o autor desse testemunho, desse texto portador da memória de um momento histórico, vivenciado pelos moçambicanos e que, hoje, é lembrado não só pelos moçambicanos, mas por povos que compartilharam da mesma experiência.

Por ser a única prosa publicada em Moçambique, no período colonial, acaba por ser referenciada como marco histórico e, por isso, trataremos aqui como um manifesto. De acordo com Norberto Bobbio (1997), em Os intelectuais e o poder, o manifesto tem sido "a forma típica do protesto dos intelectuais, do mesmo modo que a greve é a forma típica do protesto operário" (p. 57). Para ele, o manifesto tem como objetivo, dentre outros, assumir um caráter de denúncia, do protesto e da ameaça de represália. Segundo Bobbio, ao ser lançado à opinião pública, mesmo que indiretamente, o manifesto pode "assumir formas de advertência, de uma repreensão, de um convite a não se deixar enganar, de um convite a vigiar, de uma exortação e, nas formas mais graves, de um incitamento" (p. 61). O crítico italiano acredita que seja um dever do intelectual a tarefa de conscientizar a opinião pública dos oprimidos sobre os perigos que ameaçam a conservação de seus direitos irrenunciáveis. Defende, então, que o manifesto deveria ser veiculado em jornais de grande circulação, o que não ocorre e acaba por contribuir para que o manifesto circule em veículos cuja recepção se efetive entre possíveis signatários, gerando um ciclo vicioso, impedindo que o manifesto chegue aos destinatários que mais precisam dessa iluminação.

Entretanto, este não é o único ponto de fragilidade do manifesto para o autor. Bobbio situa as autoridades políticas como, também, um interlocutor do intelectual, já que um dos objetivos do manifesto é poder "influir de algum modo sobre o comportamento daquela autoridade" (1997, p. 62). Mas o autor vai apontar problemas que permeiam essa comunicação e influenciam nos resultados alcançados pela enunciação, que é a influência dos homens de cultura sobre os homens políticos. Ele explica, em primeiro plano, que a enunciação do intelectual deve ter prestígio para ser considerado e aceito pelos políticos, 
que podem não partilhar dos pressupostos apresentados pelo manifesto, por razões relacionadas à carência de informações precisas e à ausência de imparcialidade. Em Bobbio diferente de Said, que exorta à agudez da crítica, mesmo aos iguais, mas defende a localização do discurso, do pensamento - o intelectual precisa atuar como um juiz: imparcial, para "decretar" o que é ou não é justo.

Em segundo plano, no problema da comunicação entre os homens de cultura e os homens políticos, aparece a validade dos argumentos que, conforme Bobbio, devem considerar as exigências do "auditório", uma condição que só se alcança quando há um apelo aos valores comuns ou então quando o enunciador, no caso, o intelectual, conduz o manifesto de forma flexível, incorporando os valores de seus interlocutores, os políticos. Para o italiano, é o que falta nos discursos dos homens de cultura dirigidos aos homens políticos, “esta comunhão de valores comuns ou a aceitação dos valores alheios" (1997, p. 63) e, por isso, é um diálogo difícil, que torna o protesto dos intelectuais destinado "a restar letra morta" (1997, p. 64). Citando Weber, Bobbio considera que esse diálogo configura-se como um choque entre duas morais diversas: a do intelectual, embasada pela ética da convicção, em que as ações são guiadas pelo dever, sem considerar as consequências; a do político realista, embasada pela ética da responsabilidade, em que são consideradas as consequências das ações.

O terceiro ponto de crítica de Bobbio a essa comunicação entre o intelectual e as autoridades políticas diz respeito à influência pela ameaça, que deveria estar relacionada a uma sanção sofrida pelo Estado, por não ter seguido as diretivas do manifesto. É, segundo ele, o ponto em que se concentra a completa ineficácia da interlocução, pois, mesmo que existisse uma sanção aplicável ao Estado, seria difícil que se tornasse executável.

Diferente do modelo de intelectual apresentado pelo crítico italiano - imparcial, sem argumentos válidos e descrente num resultado positivo ao seu manifesto -, o intelectual moçambicano soube muito bem identificar seu lugar de fala, construir com argumentos consistentes seu manifesto e arquitetar a sanção ao poder colonial. Considerando Luís Bernardo Honwana - intelectual nascido sob o sistema colonial português em Moçambique 
-, sua obra e enunciação, julgamos que seu discurso esteja situado ao lado dos oprimidos pela colonização europeia. Seu manifesto, a obra Nós Matamos o Cão-Tinhoso, surge em contexto colonial, portando uma mensagem de natureza anticolonial, um contradiscurso, direcionado aos colonizados, mas também aos colonizadores.

Aos seus iguais, Honwana direciona uma mensagem de alerta aos males da colonização, exortando-os a uma tomada de consciência, no que diz respeito ao lugar que a administração portuguesa reserva ao nativo negro na sociedade colonial. Como previsto por Bobbio (1997), é possível entrever que a comunicação, nesse caso, também tenha se estabelecido entre os assimilados. Os demais interessados - nativos que ficaram à margem do sistema educacional colonial -, por não serem alfabetizados na língua do colonizador, não conseguiram acessar essa literatura, portanto esse manifesto ${ }^{2}$. Aos homens políticos, o poder colonial, a mensagem é de reivindicação da descolonização do território, tendo como argumentos consistentes o racismo e a desigualdade social a que são submetidos os não brancos e não europeus alocados na colônia. A sanção que seu manifesto apresenta para os representantes políticos é, contrapondo os pressupostos de Bobbio, a revolta do colonizado, que pode ser manifestada, inclusive, através da luta armada, liderada pelos movimentos de libertação.

É sobre esse intelectual que Frantz Fanon (1968) falará em Os condenados da Terra, mostrando como se deu sua formação e atuação no contexto colonial. Ele apresenta esse "homem de cultura colonizado" de uma forma que muito atrai o nosso olhar, pois o apresenta como aquele que está na base da organização dos movimentos de libertação e, mais uma vez, rasurando a perspectiva de Bobbio, esse intelectual atua nas duas principais frentes do movimento: ele é político, porque integra os partidos nacionalistas; é homem de

\footnotetext{
${ }^{2}$ Lembrando que podemos, aqui, trabalhar com a hipótese dos serões da FRELIMO - do qual Cabaço tocou e trouxemos anteriormente -, para a leitura de obras literárias, consideradas como importantes para o movimento. Acreditando que Nós matamos o Cão-Tinhoso tenha sido uma dessas leituras e tendo o conhecimento de que a FRELIMO era composta não só de assimilados e brancos, mas de pessoas ligadas às tradições culturais e que não foram incluídas na política de assimilação, podemos inferir que a leitura feita, aos moldes das culturas locais, pela tradição oral, pode ter atingido também os não alfabetizados em português.
} 
cultura, porque - em boa parte -, terá sua comunicação mediada pela literatura, que assume configuração de manifesto. É Fanon quem diz que "no seio dos partidos políticos, a maior parte das vezes ao lado deles, aparecem homens de cultura colonizados. Para esses homens a reivindicação de uma cultura nacional, a afirmação da existência dessa cultura, representa um campo de batalha privilegiado" (1968, p. 173).

Fanon pontua que o "intelectual colonizado" tem sua tarefa limitada, mas fala em limitação, em consideração ao lugar de ambiguidade ocupado por esse intelectual, que foi formado pela cultura europeia, mas fala para seu povo. Acredita, no entanto, que deve “apesar disso, contribuir em grande parte para sustentar, para legitimar a ação dos homens políticos" (p. 181). Fanon explica que há um esforço por parte do intelectual colonizado, que traduz a tomada de consciência, referente ao perigo de "romper as últimas amarras com seu povo", a saída identificada, então, é a proclamação de uma cultura nacional, que o salvaria da supremacia da cultura europeia. Assim, segundo ele, investe num retorno às raízes e, num processo de escolha - aquela que deve ser feita pelo intelectual, da qual nos falou Said na primeira parte do texto -, assume e descobre que será obrigado a responder pelo e como colonizado, por isso esse intelectual não tem como ser imparcial.

Essa atitude do assimilado de dissolver-se no meio da massa colonizada, conforme expõe o filósofo, desestabiliza a lógica do jogo traçada pelo colonialista, pois isso, segundo ele, representa uma falha no trabalho realizado pela empresa colonial. Fanon pontua que a constatação, para o "assimilado", da instabilidade que causou ao sistema, torna-se uma motivação para que ele proceda na sua recusa ao mundo branco. Segundo o autor, nesse momento, o intelectual colonizado vive "a fase da consciência em processo de libertação" e decide exprimir isso. No plano poético, o filósofo coloca que essa expressão atinge alturas insólitas, num primeiro momento, pois há uma busca forçada pelos costumes e tradições, que acaba numa procura pelo exotismo.

Fanon afirma que, quando o "intelectual colonizado" - doravante preferimos chamar de colonizado intelectual/intelectual africano, pela ambiguidade da expressão, que pode levar ao entendimento de que esse intelectual pensa de forma colonizada - lança-se 
ao trabalho de produzir obra cultural, ele não se percebe utilizando a língua do colonizador porque a reveste das línguas maternas para torná-la mais próxima do povo, pois para ele essa é uma forma de pensar a língua que se pretende nacional. Mas o martinicano faz uma crítica a esse respeito e pondera que, ao retornar ao povo através dessas obras culturais, o colonizado intelectual comporta-se como um estrangeiro, pois as ideias e preocupações que lhes aflige não coincidem com as do povo. Essa cultura para a qual esse intelectual inclina-se não passa de "um estoque de particularismos" e isso, para o filósofo martinicano, é simplificar a cultura, algo que coloca esse intelectual na contramão da história e do próprio povo, pois ao tentar descrever uma verdade nacional, ele volta-se para o passado, num movimento não natural.

O segundo momento da produção desse homem de cultura é marcado, no texto de Fanon, pelo entendimento de que para fazer uma obra nacional, em contextos coloniais, é preciso entrar em contato com a realidade nacional. Essa realidade corresponde ao momento histórico da luta, por isso a obra precisa ser um "verdadeiro convite à reflexão, à desmistificação, ao combate". Nesse sentido, Fanon postula que a utilização do passado sirva para abrir o futuro e fundar a esperança, que só estará garantida, à medida que esse intelectual estiver engajado no combate nacional. Para ele, o nacional constrói-se no "conjunto dos esforços feitos por um povo no plano do pensamento para descrever, justificar e cantar a ação através da qual o povo se constituiu e se manteve" (p. 194), situado, portanto, no centro da luta de libertação.

Outra característica do colonizado intelectual evidenciado por Fanon (1968) está relacionada ao fato de, na maioria dos casos, ele extrapolar o nacional e se lançar como porta-voz não só de um povo em particular, "de Angola ou do Daomé", mas a partir do continente africano, em torno da ideia unificada de negritude. Isto porque, segundo ele, quando o intelectual se lança num combate contra as mentiras coloniais, acaba por lutar em escala continental, afinal quando o colonialismo condenou o negro, ele não localizou aqui ou ali. A condenação, também se deu em escala continental, por isso o colonizado 
intelectual, ao renunciar a cultura ocidental, portanto europeia, ele passa a proclamar e afirmar uma cultura africana, por isso sua reivindicação passa a ser sincrética e continental.

No entanto, para Fanon, a racialização das reivindicações dos homens de cultura africanos - essa opção por falar em âmbito continental, ou mesmo universal, a partir do conceito de negritude, que se fundava numa ideia de sociedade cultural e abarcava, inclusive, a diáspora negra - acaba por conduzi-lo a um beco sem saída. Primeiramente, o autor direciona sua crítica ao fato de essa uniformização ser algo do pensamento colonialista. Depois, aponta a fragmentação dessa ideia de cultura, que esbarra na realidade dos problemas que assolavam a preocupação dos intelectuais negros. O fato de os problemas do negro norte-americano, por exemplo, não serem os mesmos do negro senegalês e assim por diante. Então os colonizados intelectuais "compreenderam que toda cultura é antes de tudo nacional" (p. 180).

O que Fanon defende é que a cultura africana se substancia a partir da luta dos povos e não em torno de cantos, poemas e folclore. Nesse caso, a tarefa do colonizado intelectual - ou, melhor dizendo, os homens de cultura negro-africana - está na contribuição para a libertação do continente. Mas é o próprio que vai mostrar como, pela literatura, é possível perceber, em três momentos, as fases que marcam a relação, de atração e repulsa, do colonizado intelectual com relação à cultura europeia, bem como do seu engajamento com a luta pela libertação.

O autor descreve uma primeira fase, que denomina como período assimilacionista, marcada por produções filiadas às produções literárias da metrópole. Aqui, segundo ele, os intelectuais interessam-se por mostrar que assimilou a cultura europeia. O segundo momento, que denomina como literatura de pré-combate, está relacionado com o momento da recusa à educação europeia e na busca incessante do passado de seu povo, por isso corresponde a um período de mal-estar, de angústia, experiência de morte, mas será dominada, também, pelo humor e pela alegoria. O terceiro momento, o do combate propriamente dito, que pode ser considerado também como literatura revolucionária ou literatura 
nacional, é configurado pela função de tirar o povo da letargia e despertá-lo, exortando-o à luta.

Segundo Fanon (1968), essa fase traz homens e mulheres, que, pela experiência da luta - o cárcere, as matas ou a espera da execução -, vêm-se a fazer obra literária, imbuídos pela "necessidade de falar de sua nação, de compor a frase que exprime o povo, de se fazer porta-voz de uma nova realidade em atos" (p. 185). Esse pode ser o caso de Honwana que, além de ter sua produção datada no período da luta anticolonial em Moçambique, em resposta à entrevista aplicada por nós, numa questão em que tratava do lugar da literatura em sua vida, disse-nos:

Passo a vida a jurar que não deixei de escrever. As pessoas exigem a evidência. Tenho publicado ensaios sobre os temas mais diversos incluindo literatura - mas parece que isso não conta. É engraçado ser mito. Quando me cansar disso vou soltar a ficção medíocre que tenho produzido. (HONWANA, ANEXO A)

A resposta do autor, ao que parece, põe o texto literário e os ensaios publicados por ele como equivalentes e portadores de uma única proposta: refletir sobre a cultura e a nação moçambicanas. É o que podemos perceber em uma de suas falas:

Não sei se realmente sou escritor. Acho que apenas escrevo sobre coisas que, acontecendo à minha volta, se relacionem intimamente comigo ou traduzam factos que me pareçam decentes [...] Este livro de histórias é o testemunho em que tento retratar uma série de situações e procedimentos que talvez interesse conhecer. (HONWANA, 2010b) ${ }^{3}$

Sobre a relação da intenção a intenção da obra e seu engajamento com o movimento de libertação de Moçambique, ele declara:

${ }^{3}$ Hoje Macau, outubro de 2010. 
Esforcei-me para que não houvesse essa parte panfletária. Devo dizer que me sinto gratificado, pois o eventual valor literário dos textos transcende o valor informativo deles sobre uma determinada época. Portanto, não são apenas testemunho duma época, mas também como construção literária, um exercício ficcional. (HONWANA, 2010b)

Percebemos que a preocupação do autor em torno da cultura, da política e da unidade nacional moçambicana é algo que pode ser percebido na obra, mas também frequente em seus ensaios. Ele tem se debruçado sobre a necessidade que se tem de pensar, ainda hoje, uma unidade mais democrática, inserindo os povos que ainda estão alheios aos processos decisórios, no que diz respeito aos rumos da nação. O que ele relaciona com a forma de apropriação da Língua Portuguesa, enquanto língua oficial, em caráter obrigatório, sendo que ainda há uma maioria de moçambicanos que não domina o português. Isso, supostamente, coloca-o junto aos escritores apresentados por Chabal (1994), que produziram uma "escrita da circunstância", já que não voltou a escrever outra obra de ficção, o que não o minimiza enquanto escritor, mas evidencia a coerência do intelectual, que não deixou de pensar e falar pelo povo.

Entretanto, essa classificação de Chabal, é questionável, pelo menos no tocante à Honwana. Primeiramente, colocamos a importância de sua obra para a história literária de Moçambique. Junto com outros autores e poetas, Honwana faz parte do movimento fundacional da literatura moçambicana. Além disso, não podemos deixar de exaltar a riqueza literária de seu texto que, de forma inteligente e genial, em poucas páginas, com tão poucas imagens, tem tanto a dizer sobre Moçambique, sobre a colonização portuguesa, sobre a descolonização das mentes e, consequentemente, do território. Por fim, como o próprio autor disse-nos, ele não parou de escrever e afirma: "quando me cansar disso, vou soltar a ficção medíocre que tenho produzido”. A fala de Honwana pode indicar, apenas, que ele não tem publicado seus escritos, mas não que tenha encerrado sua atividade literária.

Em Nós matamos o Cão-Tinhoso, Honwana pensa e questiona a organização da sociedade colonial. E o que ele descreve e denuncia em seu texto é muito próximo ao que é apresentado por José Luís Cabaço (2009), em seu estudo sociológico que trata das políticas 
identitárias, do colonialismo e da libertação de Moçambique. Também vemos semelhança entre a construção que ele faz do "assimilado", através dos narradores dos seus contos, e do perfil desse sujeito, apresentado pelos estudos de Frantz Fanon (1961) e Kabenguele Munanga (1988).

Em seu estudo, Munanga (1988) exibe uma sociedade colonial dividida em duas classes antagônicas e desiguais: de um lado a sociedade colonial, formada pelos colonizadores europeus, que tinham a função de dominar política, econômica e espiritualmente os povos dominados; do outro lado, a sociedade colonizada, dos povos submetidos, formada pelos "nativos" e pelos estrangeiros não brancos, de origem não-europeia. Sem falar na parcela da "sociedade nativa" que vivia fora desse contexto social e levava uma vida totalmente sem recursos.

Honwana apresenta o espaço ocupado pelo colonizado, marcado pela pobreza. Sob o olhar do "assimilado", a sociedade colonial moçambicana vai sendo apresentada de modo a denunciar essa cisão entre os dois mundos. Primeiramente, notamos que os adultos não negros das narrativas são sempre identificados pelo cargo que ocupam na sociedade colonial e em letra maiúscula: a "Senhora Professora", o "Senhor Administrador", o "Doutor da Veterinária", o "Senhor Padre". Percebemos também que esses adultos relacionam-se com o colonizado - Ginho, Isaura, Vírgula Oito - demarcando a autoridade, a superioridade e desprezo do branco em relação ao mundo do nativo, negando-lhe, inclusive, sua condição de ser humano. Honwana fala sobre essa divisão e relata:

Curiosamente, Moçambique era um lugar racista, com uma separação absoluta entre brancos e pretos. Alguns dos meus companheiros brancos viviam na parte europeia, onde funcionava o cineclube e as instituições. Era preciso uma habilidade especial para nos intrometermos e fazermos parte desse mundo, que nos era proibido (HONWANA, 2010a).

O autor conta, inclusive, que sua primeira prisão, ocorreu por, justamente, ele subverter essa regra dos espaços delimitados para brancos e pretos e tentar adentrar o lado europeu, o que ele chama de "zona de cimento", em oposição à “zona de caniço", espaço 
dos colonizados. Reagiu a uma ação policial e acabou sendo preso por "agressão à autoridade":

A primeira vez que foi preso, já jornalista, foi justamente por pisar a "zona de cimento". Foi interpelado pela polícia por andar por ali e instado a identificar-se. De nada lhe valeu a carteira profissional. O polícia deitou-o ao chão e exigiu a Caderneta Indígena ou o Bilhete de Identidade. "Engalfinhámo-nos em pancadaria e fui preso por agressão à autoridade", conta. "Era uma sociedade muito dividida e afrontar essa divisão era já uma atitude" (HONWANA, 2010a)

A declaração do autor encontra-se com a de Kabenguele Munanga (1988, p. 11) que trata da sobreposição do colonizador ao colonizado, numa relação de superioridade/inferioridade que era reforçado por "mecanismos repressivos diretos (força bruta) e indiretos (preconceitos raciais e outros estereótipos)". Essa ação era justificada, segundo Munanga, pela "missão civilizadora" da colonização, ou seja, se os povos indígenas eram considerados como animais pelos invasores e precisavam civilizar-se, teriam, dessa forma, que se submeter ao branco e à sua cultura para atingir o status de "homem civilizado".

Os papéis eram, então, exercidos da seguinte forma: os colonos, europeus radicados nas colônias, ocupavam os cargos de administrador e funcionários das colônias; os colonizados eram explorados pelo sistema e alguns, poucos, tinham a sorte, se assim pode dizer, de estudar nas escolas coloniais e depois serem enviados para a metrópole, de onde voltavam "assimilados". O "nativo", para ser considerado "assimilado", "via-se obrigado a abandonar os usos e costumes tradicionais (...) e portar-se sob as normas do sistema econômico imposto pelos colonizadores" (MUNANGA, 1988, p. 14).

Isso não pode ser considerado, de todo, negativo, pois a um dado tempo, conforme podemos ver no texto de Cabaço (2009), em relação ao "assimilado" moçambicano - e é possível observar também no texto de Fanon (1961), que apresenta uma abordagem mais generalizada, com foco na experiência da colonização -, a barreira racial foi se evidenciando para alguns desses "nativos”, frutos da política colonial de assimilação, como intransponível. Para obter sua plena dignidade, para determinados críticos, seria necessário subverter 
a lógica colonial, o que só se tornaria possível com o fim da colonização, através da luta. Foram esses "assimilados" que, com o tempo, começaram a questionar os efeitos da colonização para as colônias e estiveram à frente dos movimentos anticoloniais e de agenciamento da nação.

É válido ressaltar que nem todos os colonizados, sob o estatuto jurídico de assimilado, foram mobilizados por essa consciência anticolonialista. Segundo Cabaço (2009), alguns inclusive colaboraram junto do poder colonial. Não pretendemos defender também as forças independentistas surgindo, apenas, no seio da elite negra e urbana, pois já existia um descontentamento e uma resistência entre os camponeses e também entre os poderes tradicionais. Optamos por nos concentrar, nesse estudo, no perfil do "assimilado" que passou por um processo de tomada de consciência e que se entendendo, junto aos demais moçambicanos "nativos", como colonizado e no seu papel de intelectual, esteve à frente do movimento de libertação e buscou unificar a luta contra um único inimigo, o colonizador. Também se debruçou sobre a arquitetura do projeto de unidade nacional, pensado para aquele momento de Moçambique, que inclui o uso da língua portuguesa como língua oficial do nascente país.

\section{LA ESCRITA ANTICOLONIALISTA DE LUÍS BERNARDO HONWANA}

RESUMEN: Este artículo tiene como intención trazar un perfil más completo del escritor Luís Bernardo Honwana. Hablar sobre la escritura y la biografía de ese autor es algo relevante, pues aunque él publicó una única obra literaria, el Nosotros Matamos al Perrito-Tino (1964), se trata de un texto y un escritor emblemáticos. Sin embargo, la historiografía y la crítica que da cuenta de las producciones africanas del período colonial que presenta un material insipiente sobre su vida, su trabajo, no permitiendo, ni un investigador de literaturas mozambiqueñas, un contacto más significativo con el escenario en que surge. Además de una recopilación de material que ha sido publicado en diferentes lugares (Portugal, Macao, Mozambique y Brasil), con información reducida, pero con diferentes datos, este artículo reflexiona sobre el papel del intelectual y político ejercido por los escritores de la generación Honwana.

PALAVRAS-CHAVE: Perfil. Honwana. Nosotros matamos al Perrito-Tino. Literatura anticolonial. 


\section{REFERÊNCIAS}

CABAÇO, José Luís. Moçambique: identidade, colonialismo e libertação. São Paulo: Ed. UNESP, 2009.

CHABAL, Patrick. Vozes moçambicanas: literatura e nacionalidade. Lisboa: Ed.Vega, 1994. FANON, Frantz. Os condenados da terra. Trad. José Laurênio de Melo. Rio de Janeiro: Ed. Civilização Brasileira, 1968.

FERREIRA, Manuel. Literatura africana de expressão portuguesa. São Paulo: Editora Ática, 1987.

HONWANA, Luís Bernardo. "A cultura é o cimento mais adequado à construção dum novo país". Entrevista. In.: FERNANDO, Helder. Hoje Macau, sexta-feira, 22 de outubro de 2010a, p. 18-19. Disponível em:<https://issuu.com/hojemacau/docs/hm-22-10-10>. Acessado em junho de 2016.

. Nós matamos o Cão-Tinhoso. São Paulo: Editora Ática, 1980.

NUNES, Maria Leonor. Luís Bernardo Honwana: a escrita num só livro. Entrevista. In.: Jornal de Letras, 2 a 15 de junho de 2010b.

SAID, Edward W. Representações do intelectual: as conferências de Reith de 1993. Trad. Milton Hatoum. São Paulo: Ed. Companhia das Letras, 1993.

Recebido em: 29/09/2018. Aprovado em: 30/11/2018. 